\title{
Laryngeal mask airway in severe cervical ankylosis
}

Ray J. Defalque MD, Mary L. Hyder MD

Purpose: We present a case of the successful use of a laryngeal airway (LMA) to ventilate the lungs of a patient with severe ankylosing spondylitis for surgery requiring intense muscular relaxation. The use of an LMA in such circumstances is controversial.

Clinical features: The patient was a 61 -yr-old man with severe emphysema, a cervical spine fixed in marked anterior flexion, and reduced mouth opening $(35 \mathrm{~mm})$. The patient refused an awake tracheal intubation because of a previous distressing experience with a fibreoptic awake nasal intubation and an I I day SICU stay with controlled ventilation via an endotracheal tube. Attempts at spinal blocks had failed in the past. After administration of thiopentone and succinylcholine a \#4 LMA was inserted and the lungs were safely ventilated for a 10 min reduction of a dislocated femoral head.

Conclusion: The present view that severe ankylosing spondylitis is a contraindication to the use of an LMA may need revision in view of this and other reports of successful aimway management in patients with that disease.

Objectif : Les auteurs présentent l'utilisation efficace du masque laryngé (ML) pour la ventilation pulmonaire d'un patient souffrant de spondylite ankylosante et opéré pour une intervention nécessitant une relaxation musculaire profonde. Dans ces circonstances, l'utilisation du masque laryngé est contestable.

Éléments cliniques : Le patient était un emphysémateux avancé âgé de 61 ans. Sa colonne cervicale était fixée en flexion antérieure marquée et son ouverture buccale était réduite $(35 \mathrm{~mm})$. Le patient refusait une intubation vigile à cause d'une expérience antérieure angoissante : une intubation nasale vigile par fibroscopie et un séjour de onze jours à l'USI pour ventilation contrôlée par tube endotrachéal. Dans le passé, les tentatives de bloc rachidien avaient été infructueuses. Après l'administration de thiopentone et de succinylcholine, un ML No.4 était inséré et les poumons ventilés sans difficultés pendant dix minutes pour la réduction de luxation d'une tête fémorale.

Conclusion : L'opinion qui prévaut actuellement selon laquelle la spondylite ankylosante constitue une contreindication au ML devrait être révisée à la lumière de comptes rendus comme celui-ci qui font état d'une gestion efficace de patients souffrant de cette affection.

From the Department of Anaesthesiology, University of Alabama at Birmingham, 619 South $19^{\text {th }}$ Street, Birmingham, AL 35233-6810. Phone: (205) 934-4699; Fax: (205) 975-5963; E-mail: rdefalque@ms.jt.anes.uab.edu

Address correspondence to: Dr. Ray J. Defalque.

Accepted for publication November 30, 1996 . 
$\mathrm{F}$ IBREOPTIC awake intubation of the trachea is generally recommended as the safest method to provide inhalation anaesthesia in a patient with severe ankylosing spondylitis with a cervical spine fixed in anterior flexion, reduced oral opening, and emphysema. ${ }^{1-3}$

We present the case of a patient with severe ankylosing spondylosis who required a brief period of deep muscular relaxation during general anaesthesia to reduce a dislocated femoral head after THA. The patient adamantly refused tracheal intubation because of a recent distressing experience with an awake fibreoptic nasal tracheal intubation followed by 11 days in the SICU with controlled ventilation through a nasotracheal tube. Attempts at spinal blockade had failed in the past because of marked lumbar spinal deformity.

A laryngeal airway was inserted after intravenous injection of thiopentone and succinylcholine. The lungs were easily and safely ventilated during the 10 min procedure.

This case report supports the suggestion ${ }^{4-6}$ that an LMA may be a safe alternative to provide general anaesthesia in patients with severe ankylosing spondylitis.

\section{Past medical history}

The patient was a 61 -yr-old white man, $165 \mathrm{~cm}$ tall and weighing $65 \mathrm{~kg}$. Since the age of 17 he had had severe ankylosing spondylitis which involved the entire spine, thorax, temporo-mandibular joint, and both hips. He had been a heavy cigarette smoker until two years ago. Smoking and thoracic spondylosis had produced severe restrictive/obstructive emphysema, as shown by chest $\mathrm{X}$-rays and pulmonary function tests. Over the years, the patient had suffered multiple bouts of pneumonia; the last, accompanied by pneumothorax, had occurred one year before his present admission. At the age of 31 the patient had sustained bilateral hip fractures in a car accident and undergone left hip fusion and right total hip arthroplasty (THA). The patient had undergone two ano-rectal operations. They were performed under infiltration anaesthesia after multiple attempts at spinal block had failed.

One year before his present admission the patient developed extreme right hip pain. This could not be controlled by bed rest and large amounts of opioids and a revision of his right THA was decided upon. The patient, at the time, inhaled various bronchodilators and was taking large doses of oral prednisone and opioids. After awake fibreoptic nasal tracheal intubation the patient was anaesthetized with isoflurane in an $\mathrm{O}_{2}$ /air mixture and paralyzed with vecuronium.
The revision was difficult and took four hours. At the end of the operation, the tracheal tube was removed over a Cook airway exchanger. Even with $100 \% \mathrm{O}_{2}$ by closed face mask the patient was unable to maintain a $\mathrm{PaO}_{2}>85 \mathrm{mmHg}$ in the PACU and his trachea was reintubated over the Cook exchanger. He was taken to the SICU and controlled mechanical ventilation was administered through the naso-tracheal tube. All efforts to wean him off the ventilator failed and mechanical ventilation was maintained for 11 days. His SICU stay was complicated by atelectasis, lobar pneumonia, septicaemia, urinary tract infection, transient renal insufficiency, hyper-and-hypo-kalaemia, and fluid retention. A tracheostomy was planned for the $12^{\text {th }}$ postoperative day but on the evening of the $11^{\text {th }}$ day the patient became restless and pulled out his tracheal tube. He was able to maintain a $\mathrm{PaO}_{2}>75-80$ $\mathrm{mmHg}$ (his preoperative level on room air) with additional $\mathrm{O}_{2}$ through a face mask then a nasal cannula. $\mathrm{He}$ was transferred to the ward on the $15^{\text {th }}$ postoperative day and sent to a nursing home five days later.

\section{Present procedure}

The patient's right femoral head became dislocated during rehabilitative physiotherapy two months after the THA revision. A closed reduction in the operating room was planned for the next morning.

The 61-yr-old patient showed an extreme anteriorly flexed and immobile cervical spine. His chin was located three $\mathrm{cm}$ above the left mid-clavicular point. The oral opening between the incisors was $35 \mathrm{~mm}$. The chest was barrel-shaped and poorly mobile. A recent chest X-ray showed severe emphysema and bilateral lower lobe atelectasis. The patient was inhaling several bronchodilators and taking large oral doses of steroids ( $15 \mathrm{mg}$ prednisolone a day) and oxycodone (20-25 $\mathrm{mg}$ a day), hydrocodone (50-60 $\mathrm{mg}$ a day) and propoxyphene (400-600 $\mathrm{mg}$ a day).

The patient had very unpleasant memories of the previous awake tracheal intubation (with $2 \mathrm{mg}$ midazolam iv) and, especially, of the prolonged mechanical ventilation in SICU. Little sedation had been given in the ICU as early extubation and weaning from the ventilator were desired. The patient was adamantly opposed to an tracheal intubation; he would refuse surgery if this technique was chosen. Spinal or epidural anesthesia was not considered because of the previous failed attempts at spinal blocks and the severe deformity of the lumbar spine.

After a sphygmomanometer, two-lead ECG, and pulse oximeter were attached, the patient was given $100 \% \mathrm{O}_{2}$ via a face mask while $1 \mathrm{mg}$ midazolam and 
three doses of $50 \mu \mathrm{g}$ fentanyl were slowly injected $i v$. Then $200 \mathrm{mg}$ thiopentone and $60 \mathrm{mg}$ succinylcholine were injected in quick succession. As soon as the fasciculations subsided, the surgeons were encouraged to start the reduction. A lubricated \#8 Robertozzi nasal airway was inserted in the right nostril. The lungs were easily ventilated by mask with a mixture of $\mathrm{O}_{2} 40 \%$ in air and isoflurane $0.5 \%$. A plain \#4 LMA was inserted with some difficulty due to the narrow oral opening and the cuff was inflated with $40 \mathrm{ml}$ air. There was no audible leak and the lungs could be easily ventilated by hand, maintaining a $\mathrm{SpO}_{2}$ of $100 \%$ and a $\mathrm{P}_{\mathrm{ET}} \mathrm{CO}_{2}$ of $32-34$ $\mathrm{mmHg}$. Relocation of the hip was difficult and required several attempts over five minutes. Within the following five minutes an X-ray confirmed good reduction and a long leg immobilizer was placed.

By the end of the surgical procedure the patient was breathing spontaneously and had good pharyngeal reflexes. The LMA was easily removed after the cuff was deflated, allowing the patient to talk and to express his appreciation that he had been spared tracheal intubation. The patient was discharged to a nursing home two days later.

\section{Discussion}

In our experience, close reduction of a dislocated femoral prosthesis requires deep muscular relaxation, as that provided by succinylcholine or a spinal block. The patient's history of unsuccessful lumbar puncture precluded central neural blockade. Awake tracheal intubation before induction of general anaesthesia was the safest way to anaesthetize this patient ${ }^{1}$ and it is likely that the use of short-acting anaesthetics and muscle relaxants would have allowed safe extubation at the end of the procedure. However, the patient's adamant objection to a tracheal tube did not allow that option and forced us to look for an alternative.

Recent reports of successful use of an LMA in patients with oral openings $<20 \mathrm{~mm}^{7}$ or with severe cervical spinal deformity ${ }^{4,5,8-10}$ encouraged us to insert a laryngeal airway. We used small doses of thiopentone and succinylcholine to allow rapid recovery, should the patient's airway become difficult to maintain. We decided to insert the LMA, even after finding that we could safely ventilate the lungs with a face mask and nasal airway, in case the attempts at reducing the dislocation became protracted and additional anaesthesia and muscle relaxation were required.

This case report adds support to the proposition made by several anaesthesists ${ }^{6,8}$ that even patients with severe ankylosing spondylitis can safely be managed with a LMA.

\section{References}

1 Stoelting RK, Dierdorf SF. Anesthesia and Co-existing Diseases. New York: Churchill-Livingstone. 1993: 449.

2 Pennant JH, White PF. The laryngeal mask airway. Its use in anesthesiology. Anesthesiology 1993; 79: 144-63.

3 Fischer JA, Ananthanarayan C, Edelist G. Role of the laryngeal mask in airway management (Editorial). Can J Anaesth 1992; 39: 1-3.

4 Alexander $C A$, Leach $A B$, Thompson AR, Lister JB. Use your brain! (Letter) Anaesthesia 1988; 43: 893-4.

5 Chadd GD, Ackers JWL, Bailey PM. Difficult intubation aided by the laryngeal mask airway (Letter). Anaesthesia 1989; 44: 1015.

6 Leach $A B$, Alexander $C A$. The laryngeal mask - an overview. Eur J Anaesthesiol 1991; Suppl 4: 19-31.

7 Maltby JR, Loken RG, Beriault MT, Archer DP. Laryngeal mask airway with mouth opening less than $20 \mathrm{~mm}$. Can J Anaesth 1995; 42: 1140-2.

8 Maltby $J R$, Loken $R G$, Watson NC. The laryngeal mask airway: clinical appraisal in 250 patients. Can J Anaesth 1990; 37: 509-13.

9 Smith BL. Brain airway in anaesthesia for patients with juvenile chronic arthritis (Letter). Anaesthesia 1988; 43: 421.

10 Silk JM, Hill HM, Calder I. Difficult intubation and the laryngeal mask. Eur I Anaesthesiol 1991; Suppl 4: 47-51. 